\title{
Fine-scale temporal and spatial dynamics of epigaeic ants in Fynbos: sampling implications
}

\author{
C. Boonzaaier ${ }^{*}$, M.A. McGeoch ${ }^{2}$ \& C.L. Parr ${ }^{3}$ \\ ${ }^{1}$ Department of Conservation Ecology and Entomology, University of Stellenbosch, Private Bag X01, Matieland, \\ 7602 South Africa \\ ${ }^{2}$ Centre for Invasion Biology, University of Stellenbosch, Private Bag X01, Matieland, 7602 South Africa \\ ${ }^{3}$ Bushfire CRC, CSIRO Tropical Ecosystems Research Centre, PMB 44, Winnellie, Northern Territory, 0822, Australia
}

\begin{abstract}
Conservation and management strategies are dependent on reliable species richness information. Accurate species richness counts, especially for invertebrates, are almost impossible to obtain from sampling alone, due to the high costs and effort involved. Therefore, there is a great need to optimize sampling effort to gain maximum information from minimum sampling duration and intensity. Reliable species richness information is particularly critical for under-studied, high diversity regions, such as the Cape Floristic Region (CFR), where biodiversity is threatened by agricultural practices and urbanization. Ants (Formicidae) form an important part of the fauna of the CFR, especially as seed dispersers. This study investigated sampling effort options for maximizing ant species representivity in the region. The specific aims were to determine (i) whether a doubling in the sample duration significantly increased the number of species captured (ii) the effect of increased spatial versus temporal sampling effort on diversity estimates and (iii) the effect of adding an additional trapping method. Sampling was conducted at Elandsberg, Western Cape Province, from 20 February to 1 March 2004. Pitfall trapping was conducted in two five-day sessions and tuna-baits were used once. Species rarefaction curves were drawn and compared using EstimateS. A total of 42 species were captured and asymptotes to species richness were reached. Doubling of sample duration yielded no significant increase in species richness and was equally affected in terms of number of species as was doubling the sampling intensity. However, increasing the number of spatial replicates yielded a higher turnover in species. Baiting added no additional species to pitfall catches. Therefore, when sampling ant diversity in the CFR, investing sampling effort within seasons in spatial replication is likely to be more effective than increasing sampling duration.
\end{abstract}

Key words: species richness, Formicidae, sampling effort, Cape Floristic Region, pitfall trapping.

\section{INTRODUCTION}

A fundamental element of conservation and biodiversity management is information on species richness, i.e. the number of species in a unit area or assemblage (Gotelli \& Colwell 2001; Cao et al. 2004; Magurran 2004). Although biodiversity can be measured in a variety of ways, the most commonly used is species richness (Lande 1996; Gaston \& Spicer 2004) because it is relatively practical and simple to measure in the field (Lande 1996; Gaston \& Spicer 2004). Vast amounts of species richness information can be found in the literature and in museums (Gaston \& Spicer 2004). If the number of individuals in an assemblage is fairly evenly distributed between species, species richness can provide a good surrogate measure for other biodiversity measures, such as genetic, organismal

*To whom correspondence should be addressed.

E-mail: ckassier@sun.ac.za and ecological diversity (Gaston \& Spicer 2004). Additionally, species richness is widely used by managers, legislators and politicians, who often inadvertently equate biodiversity to species richness (Buchs 2003; Gaston \& Spicer 2004). Species richness estimates across time and space can be used to determine other measures underlying conservation strategies, such as species turnover rates, species extinction and colonization (Cao et al. 2004). Species richness and evenness values are also commonly employed to compare sites and to assess their conservation value, as well as to determine the effects of disturbances on biodiversity (Longino 2000; Cao et al. 2004; Colwell et al. 2004).

Information on species richness is especially valuable for helping to prioritize specific areas for conservation efforts in regions which are highly diverse and threatened by factors such as habitat 
destruction, invasive species and climate change (Rodrigues \& Gaston 2002; Rouget et al. 2003; Cao et al. 2004; Magurran 2004; Opdam \& Wascher 2004). One such area is the Cape Floristic Region (CFR), South Africa, which is considered a global biodiversity hotspot (Myers et al. 2000). Although much is known about plant species richness in the region (Cowling \& Hilton-Taylor 1994), insect diversity is poorly understood (Giliomee 2003). Arthropods are, however, critically important in the region, functioning as pollinators, seed dispersers and natural predators (Donaldson et al. 2003; Giliomee 2003; Witt \& Samways 2004), and arthropod diversity information is therefore invaluable for the conservation of biodiversity in the region.

Species richness counts need to be accurate to ensure confidence in conservation decisions and to meaningfully compare sites (Gotelli \& Colwell 2001). Although, species richness is the oldest and simplest measure used to describe biodiversity, it is notoriously difficult to obtain accurate measures, particularly for arthropods (Colwell \& Coddington 1994; Magurran 2004). Assemblages are often very diverse and a large sampling effort is required to represent all species (Magurran 2004). Assemblages frequently have a high proportion of rare species, which are under-represented in samples (Gotelli \& Colwell 2001; Magurran 2004).

Owing to the problems associated with obtaining accurate species richness measures, techniques have been developed that provide comparable richness estimates with quantified degrees of certainty for situations where sample representivity is insufficient (Cao et al. 2004; Chao et al. 2005). These techniques provide comparable richness estimates where sample effort across sites is unequal or insufficient (Colwell \& Coddington 1994). Nonetheless, sampling diverse assemblages with low evenness values, such as arthropod assemblages, requires large sampling effort which is highly resource intensive in terms of person power, finances and time (Colwell \& Coddington 1994; Sutherland 1996; Longino 2000; Colwell et al. 2004). At the same time, large samples result in collection of more material than necessary, which is not only time-consuming to sort, but also unethical (Jones \& Eggleton 2000). Hence, there are several important advantages to optimizing sampling effort so that maximum sampling representivity is achieved with minimum sampling effort.

Most studies that aim to quantify the species richness and composition of a region rely on taxon-appropriate sampling methods replicated within that particular region. In addition, biodiversity estimate studies, due to time constraints, commonly sample on a single occasion, where the timing of the sample coincides with the peak activity period of the taxon of interest (Davis et al. 1999; van Rensburg et al. 1999; McGeoch et al. 2002). This study therefore aimed to determine the optimal sampling effort in a given season, for a given taxon in the CFR, namely ants (Hymenoptera: Formicidae).

Ants form an important component of the fauna of the CFR and fulfill a critical role as seed dispersers for more than $20 \%$ of the plant species in the region (Johnson 1992). The most widely used and standard method for trapping groundforaging ants is pitfall-trapping (Andersen 1986; Southwood \& Hendersen 2000; Parr \& Chown 2001). Although this method is known to have biases in estimating population parameters (James 2004), it is nonetheless reliable for trapping epigaeic fauna and useful for comparative studies (Samways 1990; Southwood \& Hendersen 2000). Increasing sampling effort using pitfall trapping includes an increase in sampling intensity or an increase in trapping duration (Delabie et al. 2000; Brown et al. 2004; James 2004). An increase in sampling intensity can be brought about by increasing the sampling coverage (proportion of sampling extent represented) and/or the sample number within the extent of a given grain size, as sampling intensity is given by the product of these two (McGeoch \& Gaston 2002). Increased duration generally involves leaving the traps open for longer periods of time, or temporal repetition of trapping. Both of these measures increase sampling effort and have been demonstrated to increase the number of, especially rare, species captured (Sutherland 1996; James 2004).

This study thus investigated sampling effort options for maximizing ant species representivity, i.e. obtaining a species list that is representative of the ants in the area, when sampling a component of the CFR, namely the lowland fynbos biome. The aims were to determine, (i) whether doubling the sampling duration results in a significant increase in species richness, (ii) the relative effects of increased spatial versus temporal sampling effort on diversity estimates and (iii), what the effect of an additional trapping method is, in this case tunabaits, on the species richness obtained. 


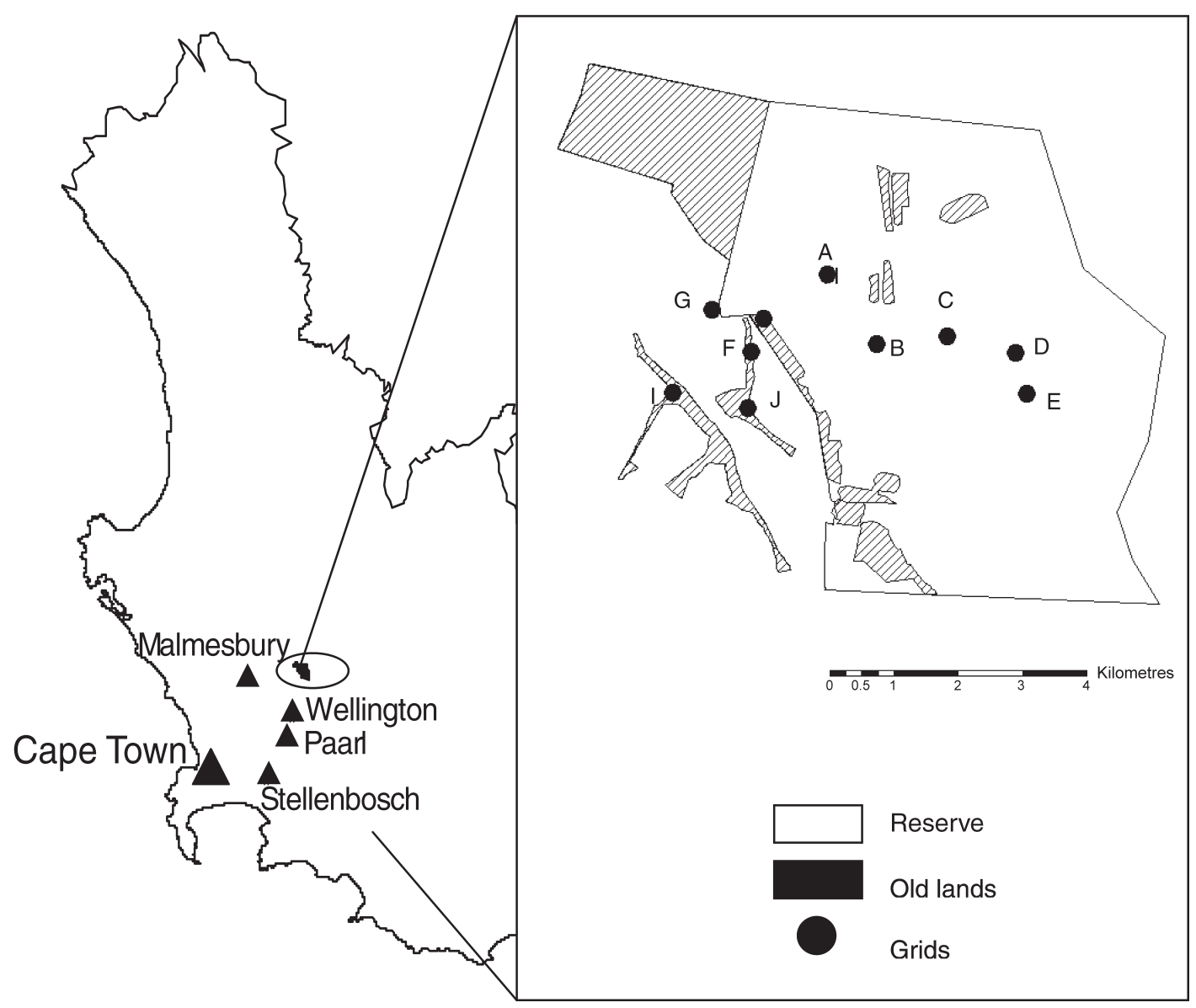

Fig. 1. Map showing study grids at Elandsberg, Western Cape Province, South Africa.

\section{MATERIAL AND METHODS}

\section{Study site and sample design}

This study took place on Elandsberg Private Nature Reserve $\left(33.27^{\circ} \mathrm{S} 19.03^{\circ} \mathrm{E}\right)$ and surrounding Bartholomeus Klip Farm, near Hermon, Western Cape Province.

The reserve, lying at the foothills of the Elandskloof Mountain range, was proclaimed in 1987 and encompasses approximately 3600 of the 5000 ha farm. The surrounding farmlands include wheat fields, and cattle and sheep grazed areas. Elandsberg has two main vegetation types, namely Swartland Alluvium Fynbos and Swartland Shale Renosterveld, both of which are critically endangered (Mucina \& Rutherford 2004). Elandsberg receives a mean annual rainfall of about $500 \mathrm{~mm}$.
The sample design consisted of 10 grids, each containing 10 pitfall traps spaced $10 \mathrm{~m}$ apart in two rows $(2 \times 5)$. The position of each grid was randomly chosen and recorded with a Garmin GPS. Grids were chosen to represent the Elandsberg area, including the reserve and natural remnants scattered between wheat fields (Fig. 1). All grids were at altitudes of between 71-170 $\mathrm{m}$ a.s.l. and were placed 200 to $250 \mathrm{~m}$ apart.

\section{Sampling}

Sampling was conducted in summer from 20 February to 1 March 2004, which includes the peak activity period for ants in the CFR (Johnson 1992). The pitfall traps used were plastic containers (150 $\mathrm{ml}$, $55 \mathrm{~mm}$ diameter, $70 \mathrm{~mm}$ deep) with screw-on caps. These were dug in level with the surrounding soil surface. The pitfall traps were covered for 
the first five days, to reduce the digging-in effect (Greenslade 1973), after which they were opened for a period of five days per sampling event. To set the traps, $50 \mathrm{ml}$ of $50 \%$ propylene glycol solution was poured into the opened pitfalls (Bestelmeyer et al. 2000). This preservative is non-toxic to vertebrates (Bestelmeyer et al. 2000), and neither attracts or repels ants (Abensperg-Traun \& Steven 1995).

After the first sampling period of five days, pitfalls were carefully removed and new traps were inserted into the same holes and reset. Pitfalls were set and removed in the same order over as short a period as possible, typically between 10:00-15:00, to ensure that they were open for equal lengths of time. The contents of the traps were poured into a net and loose soil and propylene glycol were gently rinsed off with water. The remaining individuals were then preserved in $70 \%$ alcohol.

Baiting was used as an additional sampling technique for ants. Tuna was used, as this is the most commonly used food substance to attract ants (Bestelmeyer et al. 2000; Addison \& Samways 2000). One teaspoon of shredded, tinned tuna was placed $20-30 \mathrm{~cm}$ from a pitfall trap in each grid. This was done after the first traps had been removed and new ones inserted. The baits were left for 45-60 min between 10:00 and 15:00 after which all ants feeding on the tuna were collected and placed in $70 \%$ ethanol. Leaving baits for longer does not increase the number of species found (Delabie et al. 2000).

The fauna of both pitfall traps and baits were identified under a Leica-M Series stereo-microscope. The ants were identified to genus and species level where possible, or assigned morphospecies using Bolton (1994) and Hölldobler \& Wilson (1990). Voucher specimens of each species collected were deposited at the University of Stellenbosch.

\section{Data analysis}

All pitfall data were analysed at the grid level $(n=10)$. To estimate sampling representivity (Gotelli \& Colwell 2001), rarefaction curves were compiled separately for the first five-day, second five-day and full 10-day data sets using EstimateS V7, (Colwell 2005). Species rank abundance curves were constructed (Magurran 2004) to compare the rank abundance distributions of the first and second trapping periods.

To investigate the effects of the three sampling options, data were subdivided into different categories: (1) to investigate the effects of increased sampling duration, pitfall data were divided into first five days, second five days and a combined 10-day sampling period, using all 10 grids data. (2) The effects of the increase in sampling intensity were investigated using the mean of five randomly chosen grids (five grids were randomly chosen 1000 times) and comparing the results obtained to those of the full 10 grid data set, using only the first five-day trapping period data. (3) To compare the effects of increased sampling duration and intensity, rarefaction curves were compiled using both sample-based and individual-based rarefaction curves (Gotelli \& Colwell 2001). Sample-based rarefaction curves, also known as expected accumulation curves, were compiled using the analytically calculated Sobs (Mao Tao) of EstimateS, which does not require resampling methods (Colwell 2005). This was done for the first five, second five and full 10-day sampling period data sets. Note that due to the way in which rarefaction curves are calculated, the mean of the randomly chosen five grid data as well as that of the full 10 grid data, for the first five days, are given by the first five-day curve. Sample-based rarefaction curves were used to compare data sets on the basis of species density, i.e. number of species per unit area (Gotelli \& Colwell 2001). To compare species richness for a given number of individuals, sample-based rarefaction curves were scaled by individuals.

Additionally, a spatially constrained curve for the total data set was generated manually, to investigate the effect of spatial autocorrelation on the rarefaction curves. This was done by starting at a randomly selected grid (for example A) and then determining the cumulative number of species for the nearest neighbouring grid (for example C), determined from the map of the GPS coordinates (Fig. 1), followed by the next nearest grid and so on. The process was repeated starting at each of the 10 grids in turn. The mean values for each of the 10 grid runs were then used to construct the curve. The shapes of the rarefaction curves were compared visually with that of the spatially constrained model. To formally test for the presence of spatial autocorrelation in richness and abundance, SAAP v 4.3 and Moran's I were used (Wartenberg 1989).

To estimate true ant species richness for Elandsberg, a series of nonparametric species estimators, 
provided by EstimateS, was used. This approach was used because observed species richness obtained from sampling is considered to provide a biased estimate of true richness (Colwell \& Coddington 1994). Determining which of these estimators is least biased and most accurate and precise for the specific set of data is complex, and dependent on factors such as community evenness and sampling intensity (Brose et al. 2003). Colwell \& Coddington (1994) suggest that Chao 2 and Jack 2 (Jacknife 2) perform best for small sample sizes. Michaelis-Menten Mean (MMMean) and incidence-based coverage estimator (ICE) are two additional estimators that perform well for small samples sizes (Magurran 2004). Since datasets differed in their underlying species abundance distributions and, therefore, influenced the performance of different estimators in different ways, all four of the above estimators were used for comparison (Brose et al. 2003). Species richness estimators were calculated using 1000 randomizations, with sample replacement. Although randomisation without replacement provides a more accurate species richness estimate, for statistical comparison purposes using sample replacement gives variances for the full number of samples (Colwell 2005). The ICE values were then also used in $z$-tests to determine significant differences between five and 10 days (both using 10 grids) and also five grids and 10 grids (using 10 days). The tuna-bait data are summarized in the appendix, and were excluded from all the above analyses.

\section{RESULTS}

In total, 8207 individuals, comprising five genera and 42 species, were captured across all grids over the 10-day sampling period (Appendix A). The first and second trapping periods both yielded 38 species, with four species not shared between the two. However, the second five-day sampling period yielded fewer individuals than the first (Appendix A). The highest species richness for a grid was 18 and the lowest was six species. Approximate asymptotes to species richness were reached (Fig. 2). Estimates of species richness ranged between $43.55 \pm 4.04$ (ICE) and 48.52 (MMMean) (Table 1). All four species richness estimators showed similar trends for species richness across the sampling options, with the first five days having a marginally lower species richness estimate than the second five days (Table 1).

The species captured in the first trapping period showed a clear dominance structure, with Pheidole sp. 1 being most abundant (Fig. 3). The relative abundance distribution in the second trapping period was similar to the first, although Pheidole sp. 1 and Anoplolepis steingroeveri (Forel) were both equally dominant. In the first five and second five trapping days, 26 and 27 species, respectively, had a relative abundance of less than $1 \%$.

Species accumulated more rapidly across samples in the first trapping period than in the second period. However, more species were found per individual for the second compared to the first trapping period (Fig. 2A). For an increase in sampling duration (five days vs 10 days), species richness increased from 38 to 42 species (or an estimated 4.1 species increase using ICE) (Table 1 ), which was a non-significant increase $(z=-1.50, P$ (one-tailed) $=0.067)$. An increase from one randomly selected set of five grids to 10 grids using all 10 days showed an estimated 10.72 species increase (using ICE), which was significant $(z=$ $-3.88, P$ (one-tailed $)=0.001$ ).

Comparing sampling effort options, Fig. 4 shows that increasing effort from a mean five-day, five-grid pitfall sample leads to an almost identical increase in species richness for both sampling intensity (spatial, 38 species) and duration (temporal, 38.3 species). However, species turnover, or the number of species not shared between replicates was lower for temporal (first five days and second five days) than for spatial (five randomly selected grids and five remaining grids) replicates (Fig. 5). Most of the species that were found in only one replicate were also rare in the overall sampling (Appendix A). Results of the spatial autocorrelation analysis showed that species richness and abundances of sites closer together were not more similar than would be expected by chance, as the correlograms (for each species in each period and in total) were non-significant ( $P>0.05$ in all cases). The third sampling option, tuna-bait trapping, added no new species to those already caught in pitfall traps (Appendix A).

\section{DISCUSSION}

This study investigated three different sampling options for increasing and ultimately maximizing sampling representivity of the ant assemblage in a low-lying area of the CFR. The results show that, at 

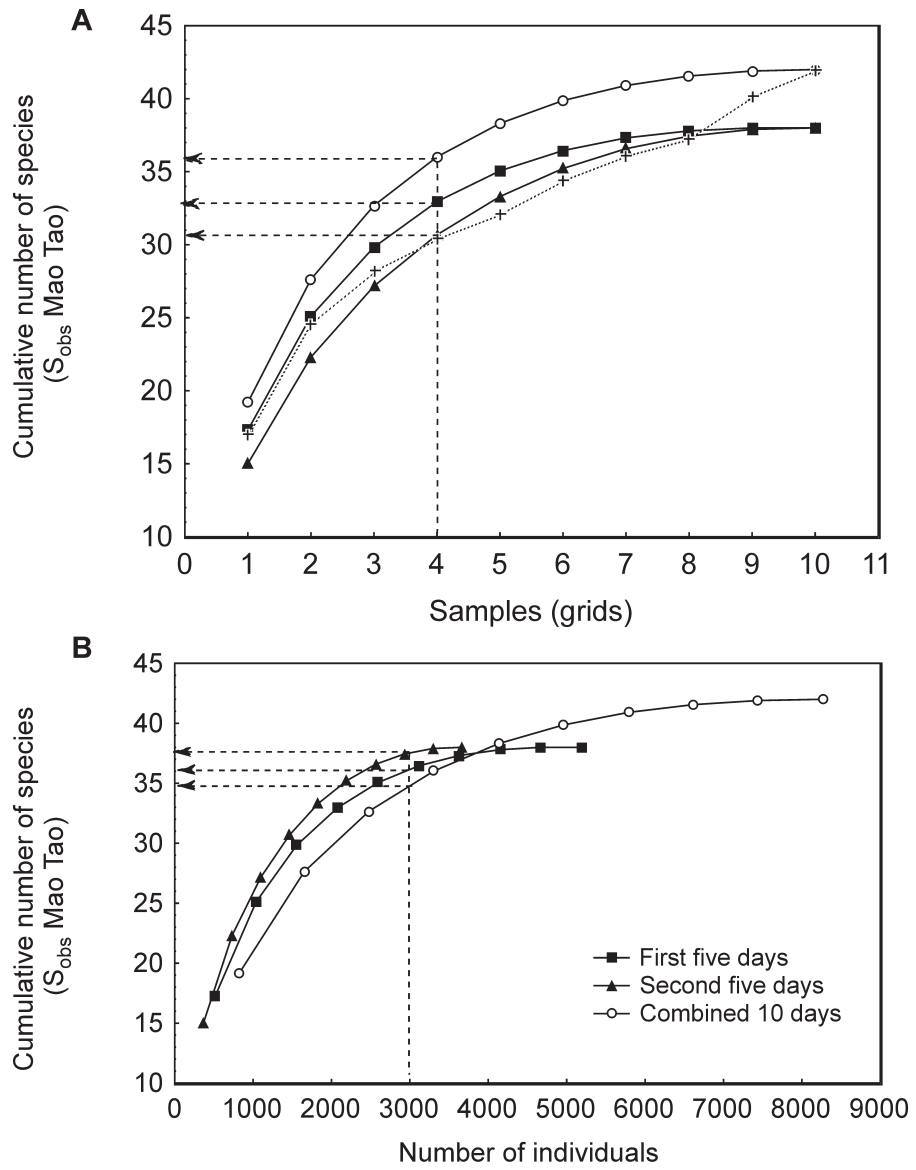

Fig. 2. Sample-based (A) and scaled by individuals (B) rarefaction curves for ant pitfall catches at Elandsberg over two consecutive five-day periods, using Sobs (Mao Tao). SC is a spatially constrained model that was generated manually.

this local site scale, increases in sampling effort in terms of increasing the sampling duration and sampling intensity (number of sampling units in an extent) result in a similar increase in ant species richness captured. Thus both sampling options appear to be equally effective for measuring species richness. However, species shared between spatial replicates was much lower than that between

Table 1. Ant species richness, number of individuals, number of species found only in one grid (unique species), and species richness estimates based on incidence-based coverage estimator (ICE), Chao 2, Jackknife 2 and Michaelis Menton Mean (MMMean).

\begin{tabular}{lccc}
\hline & First five days & Second five days & Total (10 days) \\
\hline Observed species richness (S) & 38 & 38 & 42 \\
Number of individuals & 5065 & 3142 & 8207 \\
Number of unique species & $4 \pm 3.57$ & $5.52 \pm 4.56$ & $4.48 \pm 4.1$ \\
Species richness estimators \pm S.D. & & & \\
ICE & $39.44 \pm 3.46$ & $40.59 \pm 6.07$ & $43.55 \pm 4.04$ \\
Chao 2 & $39.25 \pm 3.56$ & $40.92 \pm 6.07$ & $46.01 \pm 4.37$ \\
Jackknife 2 & $39.41 \pm 6.56$ & $39.98 \pm 9.10$ & $43.71 \pm 7.91$ \\
MMMean & 43.67 & 45.64 & 48.52 \\
\hline
\end{tabular}




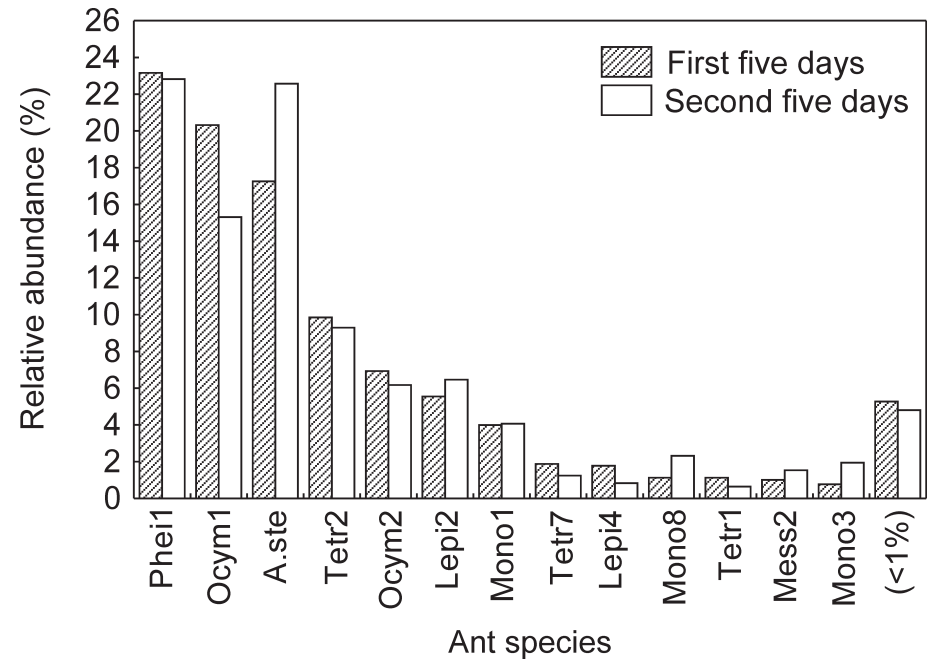

Fig. 3. Formicidae species rank abundance bar charts for two consecutive five-day periods. Phei1 = Pheidole sp. 1 , Ocym1, 2 = Ocymyrmex sp. 1, 2; A.ste = Anoplolepis steingroeveri; Tetr2, 7, 1 = Tetramorium sp. 2, 7, 1; Lepi2, 4 = Lepisiota sp. 2, 4; Mono1, 8, $3=$ Monomorium sp. 1, 8, 3; Mess2 = Messorsp. 2. The 26 species for which the relative abundance was less than $1 \%$ for both trapping periods are given in the last column $(<1 \%)$.

temporal replicates, indicating a higher turnover between spatial replicates compared to temporal ones.

Species richness of ants at Elandsberg was similar to that of other studies conducted in the CFR using pitfall trapping. Across 14 sites in the CFR moderately infested with Acacia saligna, 47 Formicidae species were found, using 10 pitfalls per site, $5 \mathrm{~m}$ apart, left open for seven days (French \& Major 2001). In the Proteoid Fynbos of the Cederberg, using a pitfall sampling design much like the one used in this study with sampling being representative of the area, 47 species were found (Botes et al. 2006). In the Jonkershoek Valley, 45 species were captured across six sites using 20 pitfalls per site which were left open for one month in 24 -hour

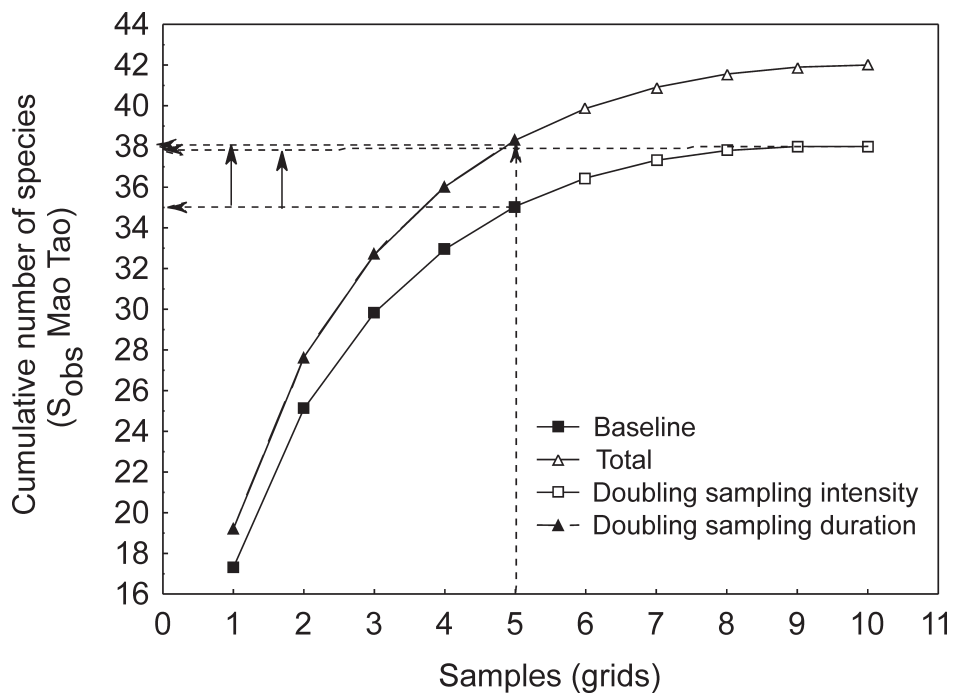

Fig. 4. Sample-based rarefaction curves showing the effects of increased sampling intensity and increased sampling duration of Formicidae pitfall catches. Baseline = sampling for five days using five grids. Doubling sampling intensity = sampling for five days using 10 grids. Doubling sampling intensity = sampling for 10 days using five grids and total = sampling for 10 days using 10 grids. 
Temporal replicates

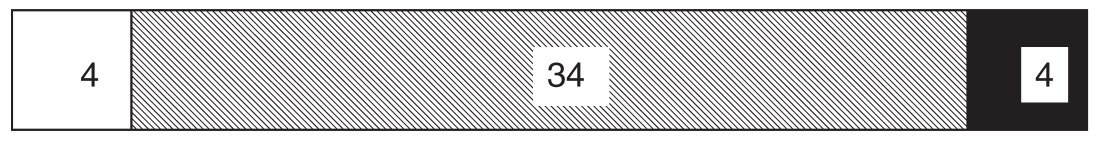

Spatial replicates

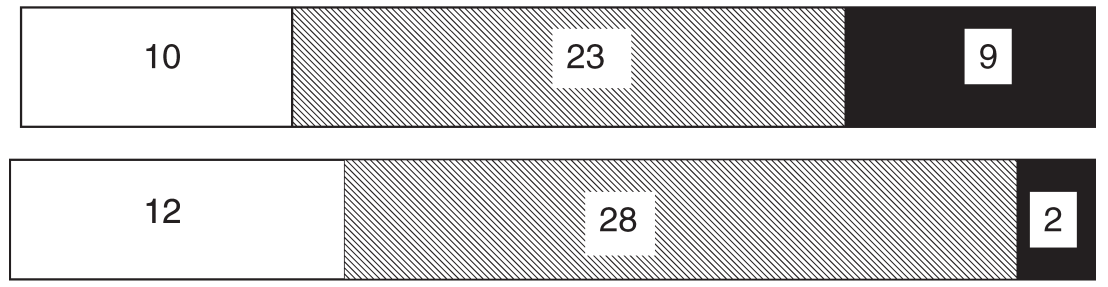

\section{Proportional species richness}

Fig. 5. Number of Formicidae species for one temporally replicated set and two spatially replicated sets. Spatial replicates were obtained by two random selections of five grids and using the remaining five to complete the set.

Species found only in first five days (temporal replicates) or randomly selected five grids (spatial replicates)

Species found only in second five days (temporal replicates) or remaining five grids (spatial replicates),

Shared species, i.e. species found in both first and second five days (temporal replicates) and species found in both five-grid replicates (spatial replicates).

intervals (Donnelly \& Giliomee 1985). The sampling conducted in this study is thus considered effective as a means of estimating the local species richness of Formicidae. Sampling during spring may result in higher species richness for Elandsberg, however species richness of samples was nonetheless typical for the CFR and hence sampling can be considered to approximate true species richness for the area.

Comparing the two consecutive five-day trapping periods, more individuals were captured during the first trapping period than in the second trapping period. The number of species was the same for both trapping periods, therefore resulting in species accumulating faster per number of individuals for the second trapping period compared to the first. Also, the second trapping period had many more species caught in only one grid, i.e. more unique species. The reason for lower numbers of individuals during the second period may be a trapping-out effect (Bestelmeyer et al. 2000). However, the cooler weather conditions during the second trapping period (minimum $11^{\circ} \mathrm{C}$ and rain on one day) are likely to have reduced ant foraging activity (Bestelmeyer et al. 2000). The first trapping period, by contrast, had temperatures greater than $30^{\circ} \mathrm{C}$, favouring thermophilic species such as Ocymyrmex spp (Hölldobler \& Wilson 1990).

Comparing the rarefaction curves of the five versus 10 grids (using the first five days' data) and first five days and 10 days (using five grids) permitted a direct comparison of the effect of a doubling in sampling duration with that of doubling in spatial replicates. The results showed an equal increase in species richness for both sampling options, but a greater number of species were replaced between spatial replicates than between temporal replicates. This turnover was greater than could be explained by spatial autocorrelation alone, as the latter analysis was non-significant. This was also apparent in the curve generated by the spatially constrained model, where species accumulated more rapidly in the rarefaction curves than the spatially constrained model predicted. Hence the spatial turnover in species was apparently determined more by habitat heterogeneity than by spatial autocorrelation. 
The greater species turnover between spatial replicates compared to temporal replicates indicates that if sampling efforts in this area were to be increased further, increasing spatial replicates is likely to be more effective than relative increases in the number of sampling days within a season. A study aimed at comparing various methods and sampling efforts for collecting ants in the Brazilian cocoa plantations, supports this idea. Increasing the sampling duration from 24 hours to seven days, for 10 samples, led to a $0.6 \%$ increase in the total estimated species richness. However, increasing the number of samples over a seven-day period from 10, to 20 and 40 led to a $15.2 \%$ and $35.9 \%$ increase in total estimated species richness, respectively (Delabie et al. 2000). This suggests that our finding applies more generally.

The third technique, implementing an additional collecting method, although recommended when sampling invertebrate assemblages (New 1998; Bestelmeyer et al. 2000), did not trap any new species. This was also found in a previous study in the CFR where various baits, including banana/ rum mixture, rotten pork and human faeces were found to be ineffective for trapping additional species (Koen \& Breytenbach 1988). Ineffective trapping with tuna-bait could result from their being monopolized by mass-recruiting dominant species (Bestelmeyer et al. 2000), which are already present in pitfall traps. Tuna-baits were not a successful additional method to use with pitfall trapping.

\section{REFERENCES}

ABENSPERG-TRAUN, M. \& STEVEN, D.E. 1995. The effects of pitfall trap diameter on ant species richness (Hymenoptera: Formicidae), and species composition of the catch in a semi-arid eucalypt woodland. Australian Journal of Ecology 20: 282-287.

ANDERSEN, A.N. 1986. Diversity, seasonality and community organization of ants at adjacent heath and woodland sites in south-eastern Australia. Australian Journal of Zoology 34: 53-64.

BESTELMEYER, B.T., AGOSTI, D., ALONSO, L.E., BRANDAO, C.R.F., BROWN, W.L., DELABIE, J.H.C. \& SILVESTRE, R. 2000. Field techniques for the study of ground-dwelling ants: an overview, description, and evaluation. In: Agosti, D., Majer, J.D., ALONSO, L.E. \& Schultz, T.R. (Ed.) Ants: Standard Methods for Measuring and Monitoring Biodiversity. 122-144. Smithsonian Institution, Washington and London.

BOLTON, B. 1994. Identification Guide to Ant Genera of the World. Harvard University Press, Cambridge, Massachusetts.

BOTES, A., McGEOCH, M.A., ROBERTSON, H.G., VAN NIEKERK, A., DAVIDS, H.P. \& CHOWN, S.L. 2006.
It is important to note that this study was not aimed at catching all the species at the site, but rather at maximizing richness for a set effort. In order to obtain a complete estimate of the species richness of an area, sampling would have to be conducted throughout the year (New 1998; James 2004). This would ensure that species that are highly seasonal would also be captured (New 1998; Delabie et al. 2000; Magurran 2004). However due to time constraints and limited resources, species richness measures in comparative studies are most often obtained using a single sampling period and trapping method (McGeoch et al. 2002).

In conclusion this study shows that sampling efforts of ants in the CFR are maximized by increasing the spatial sampling intensity rather than increasing sample duration. Therefore, it is more beneficial to sample using more grids than to sample over a longer time interval. Studies such as this are important for increasing the efficiency of sampling.

\section{ACKNOWLEDGEMENTS}

This study was supported by the National Research Foundation Grant no. GUN2053618 and the BIOTA programme, BMBF (01LC 0024A). We thank staff of Elandsberg Nature Reserve for allowing us to sample on their property, A. Botes for advice and assistance with the identification of Formicidae and two anonymous reviewers for comments.

Ants, altitude and change in the northern Cape Floristic Region. Journal of Biogeography 33: 71-90.

BROSE, U., MARTINEZ, N.D. \& WILLIAMS, R.J. 2003. Estimating species richness: sensitivity to sample coverage and insensitivity to spatial patterns. Ecology 84: 2364-2377.

BROWN, J.A., HARRIS, S. \& TIMMINS, S.M. 2004. Estimating the maximum interval between repeat surveys. Austral Ecology 29: 631-636.

BUCHS, W. 2003. Biodiversity and agri-environmental indicators - general scopes and skills with special reference to the habitat level. Agriculture, Ecosystems and Environment 98: 35-78.

CAO, Y., LARSEN, D.P. \& WHITE, D. 2004. Estimating regional species richness using a limited number of survey units. Ecoscience 11: 23-35.

CHAO, A., CHAZDON, R.L., COLWELL, R.K. \& SHEN, T-J. 2005. A new statistical approach for assessing similarity of species composition with incidence and abundance data. Ecology Letters 8: 148-159.

COLWELL, R.K. 2005. EstimateS: statistical estimation of species richness and shared species from samples. 
Version 7.5 User's Guide and application published at: http://viceroy.eeb.uconn.edu/estimates.

COLWELL, R.K. \& CODDINGTON, J.A. 1994. Estimating terrestrial biodiversity through extrapolation. Philosophical Transactions of the Royal Society of London B 345: 101-118.

COLWELL, R.K., MAO, C.X. \& CHANG, J. 2004. Interpolating, extrapolating, and comparing incidencebased species accumulation curves. Ecology 85: 2717-2727.

COWLING, R.M. \& HILTON-TAYLOR, C. 1994. Patterns of plant diversity and endemism in South Africa: an overview. In: Huntley, B. J. (Ed.) Botanical Diversity in South Africa. 31-52. National Botanical Institute, Pretoria.

DAVIS, A.L.V., SCHOLTZ, C.H. \& CHOWN, S.L. 1999. Species turnover, community boundaries and biogeographical composition of dung beetle assemblages across an altitudinal gradient in South Africa. Journal of Biogeography 26: 1039-1055.

DELABIE, J.H.C., FISHER, B.L., MAJER, J.D. \& WRIGHT, I. W. 2000. Sampling effort and choice of methods. In: Agosti, D., Majer, J.D., Alonso, L.E. \& Schultz, T.R. (Ed.) Ants: Standard Methods for Measuring and Monitoring Biodiversity. 145-154. Smithsonian Institution, Washington and London.

DONALDSON, J., NANNI, I., ZACHARIADES, C. \& KEMPER, J. 2003. Effects of habitat fragmentation on pollinator diversity and plant reproductive success in Renosterveld shrublands of South Africa. Conservation Biology 16: 1267-1276.

DONNELLY, D. \& GILIOMEE, J.H. 1985. Community structure of epigaeic ants (Hymenoptera: Formicidae) in fynbos vegetation in the Jonkershoek Valley. Journal of the Entomological Society of Southern Africa 48: 247-257.

GASTON, K.J. \& SPICER, J.I. 2004. Biodiversity: An Introduction. Blackwell Publishing Company, Oxford.

GILIOMEE, J.H. 2003. Insect diversity in the Cape Floristic Region. African Journal of Ecology 41: 237-244.

GOTELLI, N.J. \& COLWELL, R.K. 2001. Quantifying biodiversity: procedures and pitfalls in the measurement and comparison of species richness. Ecology Letters 4: 379-391.

GREENSLADE, P.J.M. 1973. Sampling ants with pitfall traps: digging-in effects. Insectes Sociaux 20: 343-353.

HÖLLDOBLER, B. \& WILSON, E.O. 1990. The Ants. Springer-Verlag, Berlin,

JAMES, C.D. 2004. Trapping intensities for sampling ants in Australian rangelands. Austral Ecology 29: 78-86.

JOHNSON, S.D. 1992. Plant-animal relationships. In: Cowling, R.M. (Ed.) The Ecology of Fynbos: Nutrients, Fire and Diversity. 175-205. Oxford University Press, Cape Town.

JONES, D.T. \& EGGLETON, P. 2000. Sampling termite assemblages in tropical forests: testing a rapid biodiversity assessment protocol. Journal of Applied Ecology 37: 191-203.

KOEN, J.H. \& BREYTENBACH, W. 1988. Ant species richness of fynbos and forest ecosystems in the southern Cape. South African Journal of Zoology 23: 184-188.

LANDE, R. 1996. Statistics and partitioning of species diversity, and similarity among multiple communities. Oikos 76: 5-13.

LONGINO, J.T. 2000. What to do with the data. In: AGOSTI, D., MAJER, J.D., ALONSO, L.E. \& SCHULTZ, T.R. (Ed.) Ants: Standard Methods for Measuring and Monitoring Biodiversity. 186-203. Smithsonian Institution Press, Washington, D.C.

MAGURRAN, A.E. 2004. Measuring Biological Diversity. Blackwell Publishing, Oxford.

McGEOCH, M.A. \& GASTON, K.J. 2002. Occupancy frequency distributions: patterns, artefacts and mechanisms. Biological Reviews 77: 311-331.

McGEOCH, M.A., VAN RENSBURG, B.J. \& BOTES, A. 2002. The verification and application of bioindicators: a case study of dung beetles in a savanna ecosystem. Journal of Applied Ecology 39: 661-672.

MUCINA, L. \& RUTHERFORD, M.C. 2004. Vegetation map of South Africa, Lesotho and Swaziland: shapefiles of basic mapping units. Beta version 4.0, February 2004. National Botanical Institute, Cape Town.

MYERS, N., MITTERMEIER, R.A., MITTERMEIER, C.G., DA FONSECA, G.A.B. \& KENT, J. 2000. Biodiversity hotspots for conservation priorities. Nature 403: 853-858.

NEW, T. R. 1998. Invertebrate Surveys for Conservation. Oxford University Press, Oxford.

OPDAM, P. \& WASCHER, D. 2004. Climate change meets habitat fragmentation: linking landscape and biogeographical scale levels in research and conservation. Biological Conservation 117: 285-297.

PARR, C.L. \& CHOWN, S.L. 2001. Inventory and bioindicator sampling: testing pitfall and Winkler methods with ants in a South African savanna. Journal of Insect Conservation 5: 27-36.

RODRIGUES, A.S.L. \& GASTON, K.J. 2002. Rarity and conservation planning across geopolitical units. Conservation Biology 16: 674-682.

ROUGET, M., RICHARDSON, D.M., COWLING, R.M., LLOYD, J.W. \& LOMBARD, A.T. 2003. Current patterns of habitat transformation and future threats to biodiversity in terrestrial ecosystems of the Cape Floristic Region, South Africa. Biological Conservation 112: 63-85.

SAMWAYS, M.J. 1990. Species temporal variability: epigaeic ant assemblages and management for abundance and scarcity. Oecologia 84: 482-490.

SOUTHWOOD, T.R.E. \& HENDERSEN, P.A. 2000. Ecological Methods. Blackwell Science, Oxford.

SUTHERLAND, W.J. 1996. Ecological Census Techniques: A Handbook. Cambridge University Press, Cambridge.

VAN RENSBURG, B.J., McGEOCH, M.A., CHOWN, S.L. \& VAN JAARSVELD, A.S. 1999. Conservation of heterogeneity among dung beetles in the Maputaland Centre of Endemism, South Africa. Biological Conservation 88: 145-153.

WARTENBERG, D. 1989. SAAP - A spatial autocorrelation analysis program v.4.3. Robert Wood Johnson Medical School, Piscataway, New Jersey.

WITT, A.B.R. \& SAMWAYS, M.J. 2004. Influence of agricultural land transformation and pest management practices on the arthropod diversity of a biodiversity hotspot, the Cape Floristic Region, South Africa. African Entomology 12: 89-95. 
Appendix A. Formicidae species and number of individuals collected using pitfall traps at Elandsberg over a 10-day period. Symbols ${ }^{*}=$ only present in first five days, ${ }^{\circ}=$ only present in second five days. ${ }^{1}$ An additional 134 individuals were caught using tuna-bait trapping. ${ }^{2}$ One individual was caught using tuna-bait trapping. ${ }^{3} \mathrm{An}$ additional 275 individuals were caught using tuna-bait trapping.

\begin{tabular}{|c|c|c|c|}
\hline Species & First five days & Second five days & Total (10 days) \\
\hline \multicolumn{4}{|l|}{ Dolichoderinae } \\
\hline Technomyrmex sp. 1 * & 5 & 0 & 5 \\
\hline \multicolumn{4}{|l|}{ Dorylinae } \\
\hline Dorylus helvolus (Linneaus) ${ }^{\circ}$ & 0 & 1 & 1 \\
\hline \multicolumn{4}{|l|}{ Formicinae } \\
\hline Anoplolepis steingroeveri (Forel) & 874 & 709 & $1583^{1}$ \\
\hline Anoplolepis sp. 1 & 18 & 2 & 20 \\
\hline Anoplolepis sp. 3 & 4 & 6 & 10 \\
\hline Camponotus fulvopilosus (DeGeer) & 7 & 2 & 9 \\
\hline Camponotus sp. 1 & 6 & 4 & 10 \\
\hline Camponotus sp. 2 & 4 & 6 & $10^{2}$ \\
\hline Camponotus vestitus (F. Smith) & 15 & 21 & 36 \\
\hline Camponotus mystaceus (Emery) ${ }^{\circ}$ & 0 & 2 & 2 \\
\hline Camponotus sp. 5 & 2 & 1 & 3 \\
\hline Camponotus sp. 6 & 1 & 1 & 2 \\
\hline Lepisiota sp. 2 & 281 & 203 & 484 \\
\hline Lepisiota sp. 3 & 12 & 1 & 13 \\
\hline Lepisiota sp. 4 & 90 & 26 & 116 \\
\hline Lepisiota sp. 5 & 12 & 18 & 30 \\
\hline \multicolumn{4}{|l|}{ Myrmicinae } \\
\hline Crematogaster sp. 1 & 20 & 3 & 23 \\
\hline Messorsp. 1 & 18 & 11 & 29 \\
\hline Messor capensis (Mayr) & 51 & 48 & 99 \\
\hline Monomorium sp. 1 & 202 & 128 & 330 \\
\hline Monomorium sp. 2 * & 3 & 0 & 4 \\
\hline Monomorium sp. 3 & 39 & 61 & 100 \\
\hline Monomorium sp. 4 & 1 & 3 & 4 \\
\hline Monomorium sp. 5 * & 13 & 0 & 13 \\
\hline Monomorium havilandi (Forel) ${ }^{\circ}$ & 0 & 1 & 1 \\
\hline Monomorium sp. 7 & 38 & 23 & 61 \\
\hline Monomorium sp. 8 & 57 & 73 & 130 \\
\hline Ocymyrmex sp. 1 & 1029 & 481 & $1510^{1}$ \\
\hline Ocymyrmex sp. 2 & 351 & 194 & 545 \\
\hline Pheidole sp. 1 & 1173 & 717 & $1890^{3}$ \\
\hline Rhoptromyrmex sp. 1 & 6 & 2 & 8 \\
\hline Tetramorium sp. 1 & 57 & 20 & 77 \\
\hline Tetramorium quadrispinosum (Emery) & 499 & 292 & 791 \\
\hline Tetramorium sp. 3 & 44 & 13 & 57 \\
\hline Tetramorium sp. 5 & 10 & 12 & 22 \\
\hline Tetramorium sp. 7 & 95 & 39 & 134 \\
\hline Tetramorium sp. 8 & 4 & 2 & 6 \\
\hline Tetramorium sp. 9 & 5 & 1 & 6 \\
\hline Tetramorium sp. 10 * & 1 & 0 & 1 \\
\hline Cardiocondyla sp. $1^{\circ}$ & 0 & 1 & 1 \\
\hline \multicolumn{4}{|l|}{ Ponerinae } \\
\hline Anochetus levaillanti (Emery) & 1 & 1 & 2 \\
\hline Pachycondyla sp. 1 & 17 & 13 & 30 \\
\hline Total & 5065 & 3142 & 8207 \\
\hline
\end{tabular}

